\title{
Correction to: The Allium triquetrum L. Leaves Mitigated Hepatotoxicity and Nephrotoxicity Induced by Lead Acetate in Wistar Rats
}

\author{
Labiba Kahalerras $^{1} \cdot$ Ines Otmani $^{1}$. Cherif Abdennour ${ }^{1}$
}

Published online: 11 January 2022

๑) Springer Science+Business Media, LLC, part of Springer Nature 2022

Correction to: Biological Trace Element Research https://doi.org/10.1007/s12011-021-03052-y

The original version of this article unfortunately contained a mistake. The section Renal Markers under the header Results should read:

Results: The mean value of renal markers in lead acetate-treated rats was significantly augmented compared to the control group, although the co-treatments with A. triquetrum leaves' extracts had a non-significant decrease in urea, creatinine $(\mathrm{Cr})$, and uric acid (UA) concentration compared to the control.Inversely, results obtained from the combined groups $(\mathrm{Pb}-\mathrm{L})$ were significantly lower than those from the $\mathrm{Pb}$ treated rats (Table 2).

The original article has been updated.

Publisher's Note Springer Nature remains neutral with regard to jurisdictional claims in published maps and institutional affiliations.

The online version of the original article can be found at https:// doi.org/10.1007/s12011-021-03052-y

Labiba Kahalerras

labiba.kahalerras@gmail.com;

labiba.kahalerras@univ-annaba.org

1 Laboratory of Animal Ecophysiology, Department

of Biology, Faculty of Sciences, University Badji

MokhtarAnnaba, 23000 Annaba, Algeria 